\title{
Improving hydrodynamic modeling of an estuary in a mixed tidal regime by grid refining and aligning
}

\author{
G. M. Jahid Hasan • Dirk Sebastiaan van Maren • \\ Hin Fatt Cheong
}

Received: 29 December 2010 / Accepted: 14 November 2011

(C) Springer-Verlag 2011

\begin{abstract}
Water levels and flows in the Singapore coastal waters are driven by the complex interactions of the Indian and Pacific Ocean tides, seasonal monsoon-driven contributions and also forced by local winds. The Singapore Regional Model was developed to simulate hydrodynamics in the Strait of Singapore which produces representative sea level variation in this region. However, resolution and alignment of the grid
\end{abstract}

Responsible Editor: Chari Pattiaratchi

This article is part of the Topical Collection on Physics of Estuaries and Coastal Seas 2010

G. M. J. Hasan $(\bowtie)$

Singapore-Delft Water Alliance,

National University of Singapore,

No. 2 Eng. Drive 2,

Singapore 117577, Singapore

e-mail: jahid01@yahoo.com

\section{G. M. J. Hasan}

Department of Civil and Environmental Engineering,

Shahjalal University of Science and Technology,

Sylhet 3114, Bangladesh

D. S. van Maren

Department of Coastal and Marine Systems,

Deltares, Rotterdamseweg 185,

Delft, the Netherlands

D. S. van Maren

Department of Hydraulic Engineering,

Delft University of Technology,

Delft, the Netherlands

\section{H. F. Cheong}

Department of Civil and Environmental Engineering,

National University of Singapore,

1 Eng. Drive 2,

Singapore 117576, Singapore system of the model with respect to depth contours in some of its subregions, i.e., the Johor Estuary area require further improvement. For this, the grid system of the model was modified and compared the simulated results with field measurements. The computed flow velocities agreed better with field observations when the grid resolution was increased. However, improving the alignment of the grid with the channel boundary (with a much lower increase in grid resolution) provided a substantially larger improvement of the model performance. The grid modification greatly influenced the computed salinity in the estuary, while water levels are slightly affected. Further analysis of model results showed a pronounced ebb tidal asymmetry generated by the O1-K1-M2 tidal constituents in the estuary.

Keywords Hydrodynamic modeling · Water levels · Tidal currents · Grid refinement and alignment · Singapore coastal waters $\cdot$ Johor Estuary

\section{Introduction}

The Strait of Singapore connects the Indian Ocean with the South China Sea and is one of the busiest shipping routes in the world. The strategic location of Singapore stimulates rapid development including ports and harbor activities, land reclamation and shore protection works, thereby heavily impacting the environment. This requires a thorough understanding of the hydrodynamics of the area and also an assessment of the impact of development on water quality and morphology. However, the hydrodynamics in the Strait of Singapore are complex for a number of reasons. First, Singapore is located in an exceptionally sharp transition zone where dominantly diurnal tides (in 
between Sumatra and Borneo) change into semidiurnal tides (in between Sumatra and Malaysia, just North of Singapore) within a distance of several $100 \mathrm{~s}$ of kilometer (Wyrtki 1961). The transition from diurnal to semidiurnal is the result of an increase of the M2 amplitude (especially in the Singapore Strait) and a decrease in diurnal amplitudes ( $\mathrm{Zu}$ et al. 2008). Secondly, numerous islands exist in the Strait, both rock outcrops (i.e., the Indonesian Riau Archipelago) and coral reef islands. Thirdly, a pronounced monsoon-driven residual flow exists, of which peak velocities may exceed tidal currents around neap tide.

Development of numerical hydrodynamic models for the Strait of Singapore has started since the 90s using two-dimensional models (Shankar et al. 1997), followed by Chen et al. (1997, 2005), Chao et al. (1999), Zhang and Gin (2000), Pang et al. (2003), Zhang and Chan (2003), Doorn-Groen (2007), etc. In recent years, several progresses were made on a three-dimensional hydrodynamic model for the region (i.e., Zhang 2006). All of the studies applied local models with rectangular grids covering water bodies only around Singapore, forced by water levels. Most of the model studies failed to reproduce the tidal currents properly. Near Singapore, a degenerate amphidromic point exists for the main diurnal constituents, resulting in high diurnal current velocities but low water level variations (Pugh 1987). Forcing a local model with only water levels will then underestimate the diurnal currents. Reproducing the complex tidal dynamics needs a model with open boundaries located far away from the area of interest. Simultaneously, the grid resolution has to be sufficiently fine to reproduce local hydrodynamic phenomena. Based on these criteria, Zijl and Kernkamp (2004) developed a boundary fitted depth-integrated hydrodynamic model (Singapore Regional Model, SRM) which stretches from the Andaman Sea to the Borneo coast to simulate the flow dynamics accurately for this region. Local refinement of the numerical grid (using the refined SRM, hereafter called SRMR), slightly improved local water level predictions but reduced the accuracy of water level predictions further away from Singapore (Ooi et al. 2009). Most emphasis in previous studies has been on the effect of grid resolution (i.e., Davies et al. 2000; Jones and Davies 2007a; 2007b). This focus on grid resolution has boosted the development of unstructured grid models. However, for same spatial resolution, unstructured grids require more computational resources for computation (Warner et al. 2010). This can lead to increased computational time depending on the grid architecture; see, for example, the review by Deleersnijder and Lermusiaux (2008). A properly designed structured grid may, therefore, still be preferred over unstructured grids depending on the required model accuracy, processes, and timescales. Structured curvilinear grids often use an Alternating Differential Implicit (ADI) scheme. The advantage of the ADI method is that the implicitly integrated water levels and velocities are coupled along grid lines, leading to systems of equations with a small bandwidth. The drawback is that the grid alignment influences the computational results in bathymetrically complex fluvial or coastal areas. In contrast with grid refinement, a subject relatively unexplored is the effect of grid alignment with depth contours on hydrodynamic simulations.

We, therefore, set out to improve the hydrodynamic predictions around Singapore through better alignment of the grid with the depth contours by setting up a locally refined and better aligned SRM (hereafter called the SRMRA). We will evaluate the effect of grid layout on water levels and currents in the Johor Estuary, located east of Singapore, by comparing three models (the SRM, the SRMR and the SRMRA) against measured water level and current data.
Fig. 1 Model domain of the Singapore Regional Model with depth variation (left panel) and a close-up view around Singapore with discharge locations (01-15) and observation locations. Constant freshwater inflow (Table 1) with zero salinity was prescribed in all the discharge locations

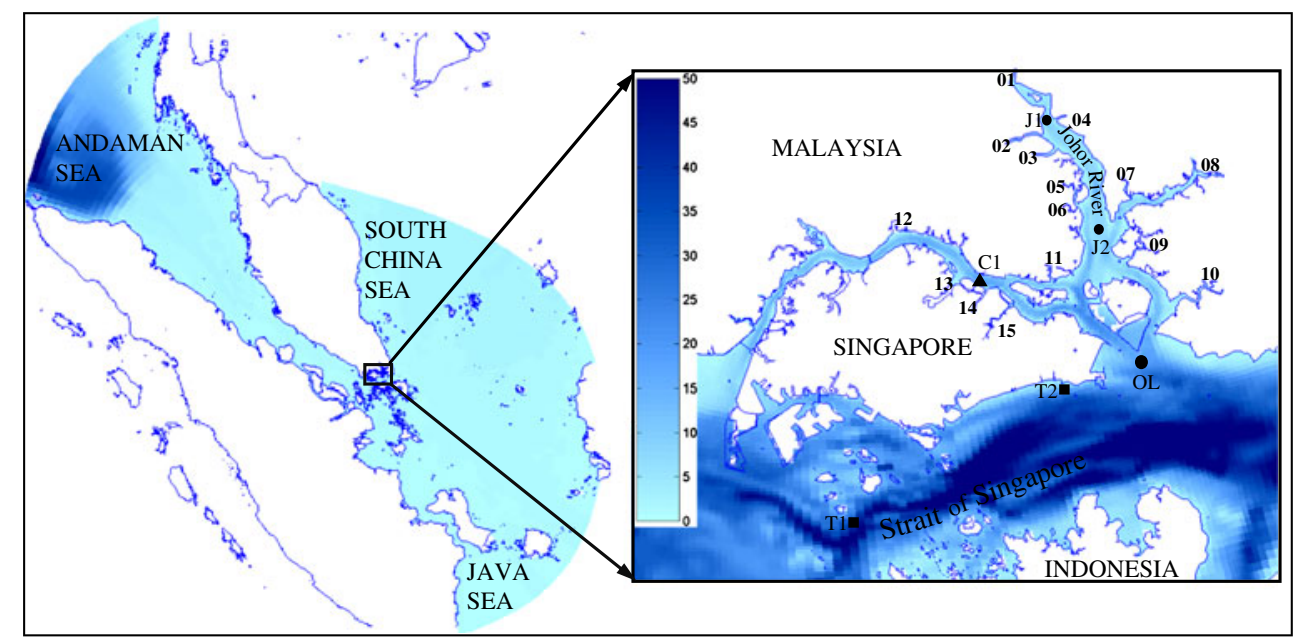


Fig. 2 Grid distribution of the Singapore Regional Model with a close-up view around Singapore. Curvilinear orthogonal grid system was designed using Delft3D for resolving the complex coastlines

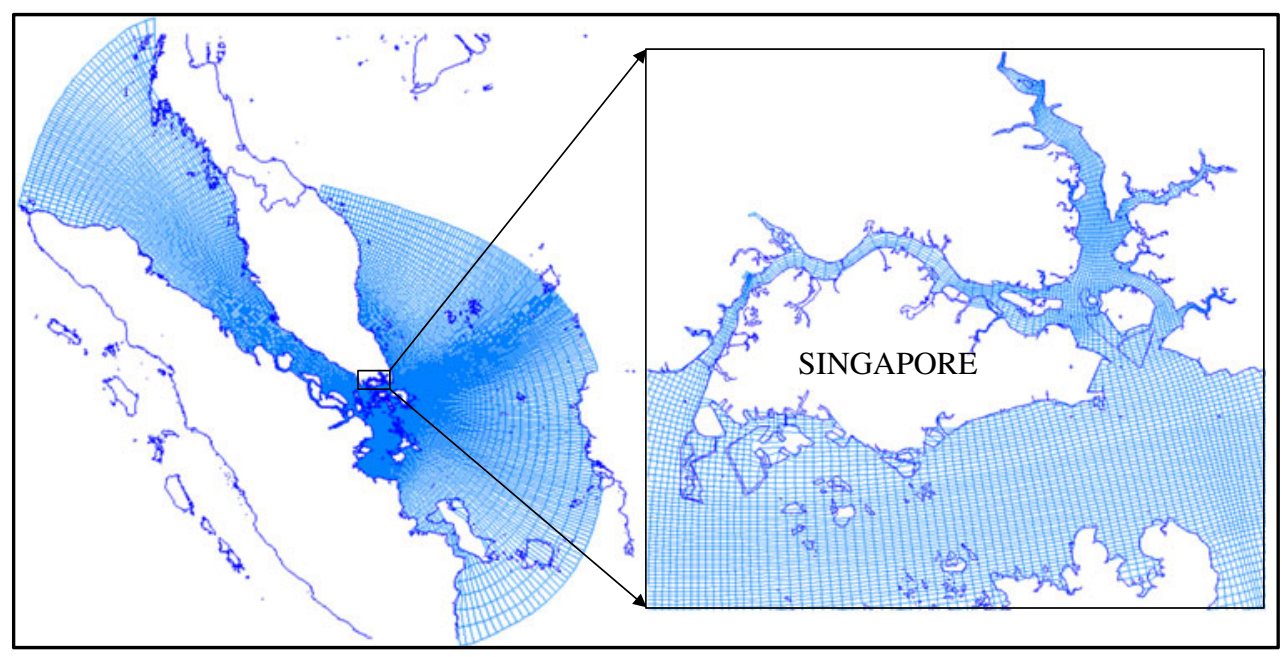

\section{Setup of the models}

\subsection{Model description}

The tidal flow is modeled using Delft3D-flow, simulating two- or three-dimensional unsteady flow and transport phenomena resulting from tidal or meteorological forcing including the effect of density differences due to a nonuniform temperature and salinity distribution. The program is based on three-dimensional shallow water equations, the continuity equations and the transport equations for conservative constituents. The set of partial differential equations in combination with appropriate initial and boundary conditions are solved with an ADI finite difference scheme on an Arakawa ' $\mathrm{C}$ ' grid system (Arakawa and Lamb 1977). The ADI method splits one integration time step into two stages; each stage consists of half a time step. In both stages, all the terms of the model equations are solved in a consistent way with at least second-order accuracy in space. The horizontal advection terms are discretized using a higher order dissipative approximation (Stelling and Leendertse 1991). Because the solution is implicit, numerical stability is not restricted by the time step or by grid size. However, the accuracy of

Table 1 Average freshwater inflow for all discharge locations (locations are shown in Fig. 1) after Hasan et al. (2010)

\begin{tabular}{cccccc}
\hline Location & $\begin{array}{c}\text { Inflow } \\
\left(\mathrm{m}^{3} / \mathrm{s}\right)\end{array}$ & Location & $\begin{array}{c}\text { Inflow } \\
\left(\mathrm{m}^{3} / \mathrm{s}\right)\end{array}$ & Location & $\begin{array}{c}\text { Inflow } \\
\left(\mathrm{m}^{3} / \mathrm{s}\right)\end{array}$ \\
\hline 1 & 56.8 & 6 & 1.6 & 11 & 1.7 \\
2 & 1.4 & 7 & 2.6 & 12 & 7.6 \\
3 & 3.8 & 8 & 5.7 & 13 & 5.0 \\
4 & 2.1 & 9 & 0.8 & 14 & 1.2 \\
5 & 0.8 & 10 & 2.2 & 15 & 2.0 \\
\hline
\end{tabular}

the flow decreases with increasing time step from accurate solutions as long as the Courant number is less than $4 \sqrt{2}$ (Stelling 1984). For the SRM and SRMRA, this criterion is fulfilled with a time step of $4 \mathrm{~min}$, but for the SRMR, $2 \mathrm{~min}$ are needed. In this study, the model was simulated in depthaveraged and in three-dimensional mode. Meteorological boundary conditions, i.e., wind forcing, are neglected.

\subsection{Model applications}

The three models used in this study are the Singapore Regional Model (SRM), the Refined Singapore Regional Model (SRMR) and the Refined and Aligned Singapore Regional Model (SRMRA). All three models were run for 1 year (Jan to Dec 2004), but this paper particularly focuses on one spring-neap cycle. The models cover part of the two large water bodies surrounding Singapore, the South China Sea in the east and the Andaman Sea in the west. A small portion of the Java Sea is included in the southern domain of the model. The model features a boundary fitted curvilinear orthogonal grid system to simulate water levels and flow patterns. Figure 1 shows the model domain with its depth variations. The figure also shows the observation locations (T1, T2, C1, J1, J2 and OL) and fresh water discharge locations (01-15). The bathymetry of the model mostly based on the Admiralty charts with a maximum depth of about $2 \mathrm{~km}$ in the Andaman Sea and about $160 \mathrm{~m}$ in the Strait of Singapore. Figure 2 displays the grid system of the model with a close-up view around Singapore. The grid system follows the general orientation of the deep channel in the Singapore Strait. The grid cell size increases from $200 \mathrm{~m}$ to $300 \mathrm{~m}$ around Singapore up to $15 \mathrm{~km}$ at the open boundaries.

The model is forced at its offshore open boundaries by eight main tidal constituents (Q1, O1, P1, K1, N2, M2, S2 and $\mathrm{K} 2$ ) and residual flows. The residual flows are nontidal 
Fig. 3 Grid distribution of the Singapore Regional Model (SRM) and Singapore Regional Model Refined Aligned (SRMRA). The SRMR is the SRM model locally (through domain decomposition) refined with a factor 3 and, therefore, not shown. The boundary locations of SRMR and SRMRA are identical to the SRM shown in Fig. 2
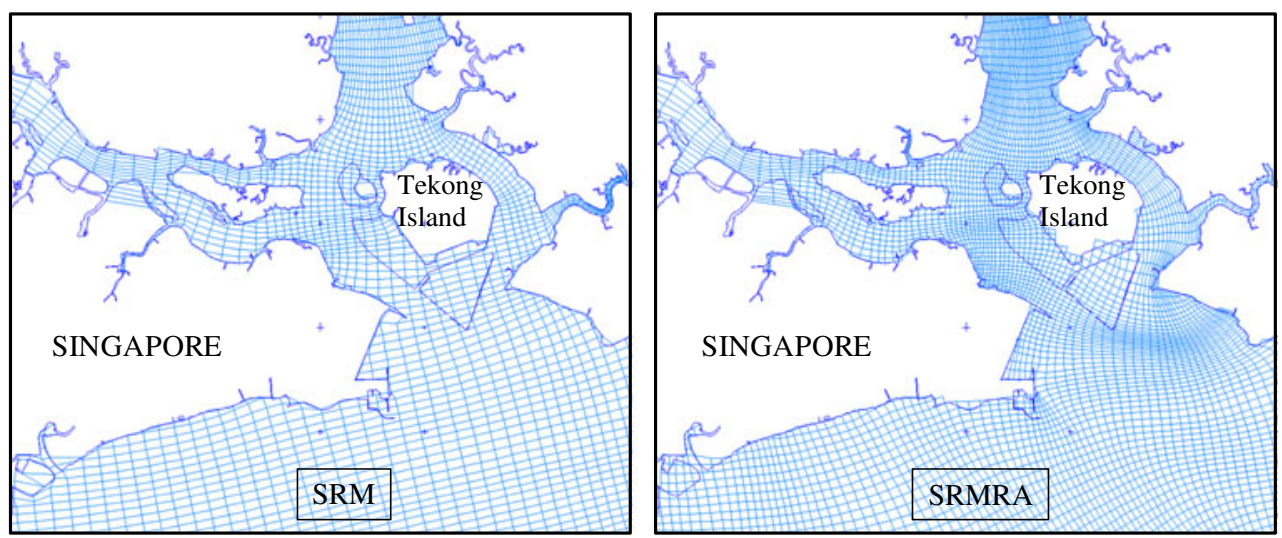

seasonal variation of the mean water level and were prescribed as a spatially and temporally varying water levels derived from satellite imagery with proper calibration as described by Twigt (2007). The salinity at the offshore open boundaries was set to 31 ppt. A constant freshwater inflow with zero salinity was also prescribed in all the discharge locations as shown in Fig. 1 for the main stream of the Johor River and its different tributaries. The river flow (as shown in Table 1) was estimated using monthly accumulated rainfall data in the surrounding catchment area, which is the only available format, using the volumetric rational method as explained by Hasan et al. (2010).

The SRM was refined three times in $n$ - and $m$-directions around Singapore, as described by Ooi et al. (2009) to obtain the SRMR. Discharge, boundary conditions, roughness parameter and all other model settings are kept similar to the SRM. In this study, the SRM was refined locally up to a factor 2 to get the SRMRA. Part of the existing grid from the SRM was subsequently removed and replaced with a rotated grid following the depth contours (see Fig. 3). In the SRM, the narrow channel east of Tekong Island is represented by three to five grid cells which are oblique to the depth contours. In the modified grid, this channel is represented by six to 10 grid cells but the grid is also parallel to the depth contours. The total number of grid cells increases due to this modification but much less than for the SRMR grid cells. As for the SRMRA, boundary conditions and model settings are similar as the SRM. A summary on setup parameters for all the three models used here are shown in Table 2.

\section{Model results}

\subsection{Model validation}

The model results were validated with measured water levels and flow velocities collected by the MPA (Maritime and Port Authority of Singapore). A spring-neap tidal cycle of measured and computed water levels at T1 and T2 (within the Strait of Singapore; locations denoted with solid rectangles in Fig. 1) are compared in Fig. 4. The tidal range is approximately $1.5 \mathrm{~m}$ during neap tide and increases up to $2.5 \mathrm{~m}$ during spring tide. The water surface fluctuations obtained from the SRM model are in good agreement with the field data though some minor discrepancies exist: the observed low waters are slightly lower than the predicted low waters, and also there is a minor phase shift. Figure 5 compares the simulation results of sea level variations between the SRM, SRMR and SRMRA at the observation location OL. The SRMRA predicts lower low waters than
Table 2 Setup information of the three models (SRM, SRMR and SRMRA) used in this study

\begin{tabular}{llll}
\hline Parameters & SRM & SRMR & SRMRA \\
\hline Total number of grids & 38,600 & 270,890 & 46,360 \\
Grid sizes (m) & 80 & 26 & 46 \\
Simulation period & Jan-Dec, 2004 & Jan-Dec, 2004 & Jan-Dec, 2004 \\
Time step (min) & 4 & 2 & 4 \\
Initial condition: salinity (ppt) & 31 & 31 & 31 \\
Bottom roughness: Manning's $n$ & 0.022 & 0.022 & 0.022 \\
Horizontal eddy viscosity/diffusivity $\left(\mathrm{m}^{2} / \mathrm{s}\right)$ & 1 & 1 & 1 \\
Vertical eddy viscosity/diffusivity $\left(\mathrm{m}^{2} / \mathrm{s}\right)$ & 0.0001 & 0.0001 & 0.0001 \\
\hline
\end{tabular}


Fig. 4 Time history of simulated sea level fluctuations and its comparison with field measurements at $\mathbf{a} \mathrm{T} 1$ and $\mathbf{b} \mathrm{T} 2$ locations covering a neap-spring period
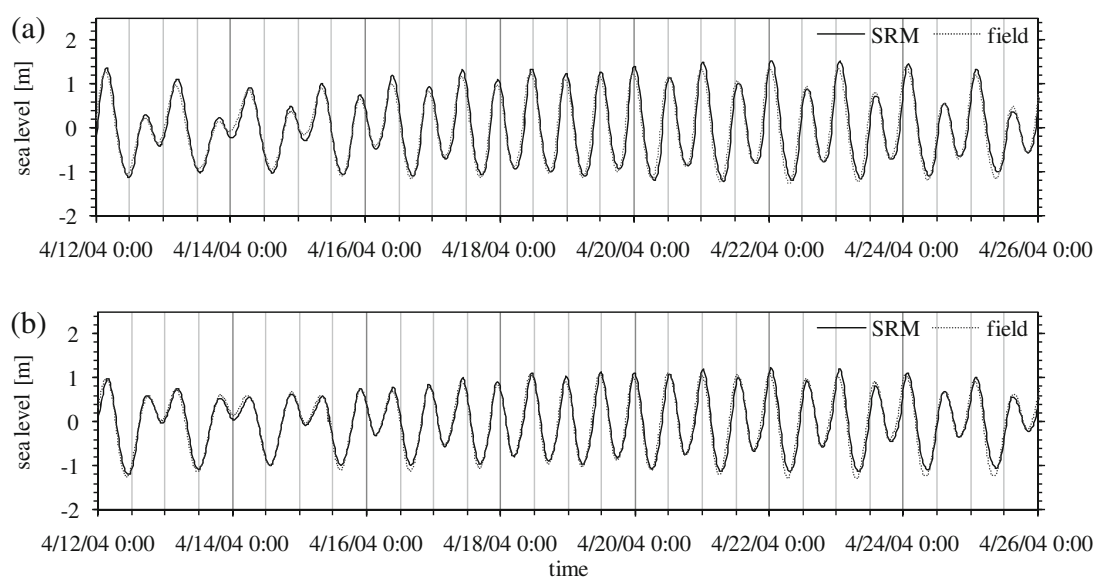

the SRM and the SRMR, indicating better performance of the SRMRA. This will be analyzed in more detail with flow velocity measurements.

Current speeds and directions are difficult to reproduce accurately since they are strongly affected by the local bathymetry. Figure 6 shows a comparison between measured and computed depth-averaged tidal current magnitude and directions at $\mathrm{C} 1$ using the SRM (same time period as for the water level comparison). The flow velocity has been measured with a bottom-mounted ADCP using a 1-m vertical resolution. The depth-averaged current was computed from the multilayer data and used for the comparison. The model reasonably predicts current speed and direction, although the ebbing current is slightly under predicted (differs approximately $10 \mathrm{~cm} / \mathrm{s}$ ). The SRM performs much worse at the location OL (location shown in Fig. 1 by a solid circle). Inspection of Fig. 7 reveals a clear dominance of diurnal flow velocities during neap tides and semidiurnal flow velocities during spring tides. The SRM fails to reproduce the direction of the flow velocity during neap tide, while the flow asymmetry is underestimated during spring tides. The $x$ (east) and $y$ (north) components of flow velocities are also displayed in the lower two panels of the figure. The north component of the simulated currents has a similar phasing as observed currents, although differences in magnitude are large (particularly during spring tide). A large difference, both in phase and magnitude, is observed in the east component. Hence, further improvement of the original SRM is required.
The results of SRMR and SRMRA are compared with field data for the same spring-neap cycle as of the SRM. Time series of observed and simulated current speed and direction at OL are shown in Fig. 8 for SRMR and in Fig. 9 for SRMRA. A major improvement is observed in the flow velocities during flood tide with the SRMR; however, ebb flow velocities are still underpredicted. Little improvement is observed in flow direction during spring tide. Whereas with the SRMRA, computed flow velocities and directions have improved substantially. The modeled flow velocities and directions are in very good agreement with observations. The ebb velocity peaks, which were underestimated by both the SRM and the SRMR (especially during spring tide), are now reasonably reproduced.

Velocity roses for depth-averaged tidal currents at the observation location (OL) computed by all the three models (SRM, SRMR and SRMRA), and its comparison with field measurements are shown in Fig. 10 to further illustrate the models performance. Results are shown for a spring-neap period $(4 / 12 / 20040: 00 \mathrm{~h}$ to $4 / 26 / 20040: 00 \mathrm{~h})$. The flow velocity computed with the SRM differs substantially from field data. The refined model (SRMR) improves model accuracy but still strongly diverges from the field data. However, significant improvement is observed from the refined and aligned model (SRMRA) which is in very good agreement with the field data. Both the SRM and the SRMR simulate flood-dominant flow velocities whereas ebb dominance is predicted by the SRMRA (in agreement with field observations).
Fig. 5 Time history of simulated with SRM, SRMR and SRMRA sea level fluctuations at the OL

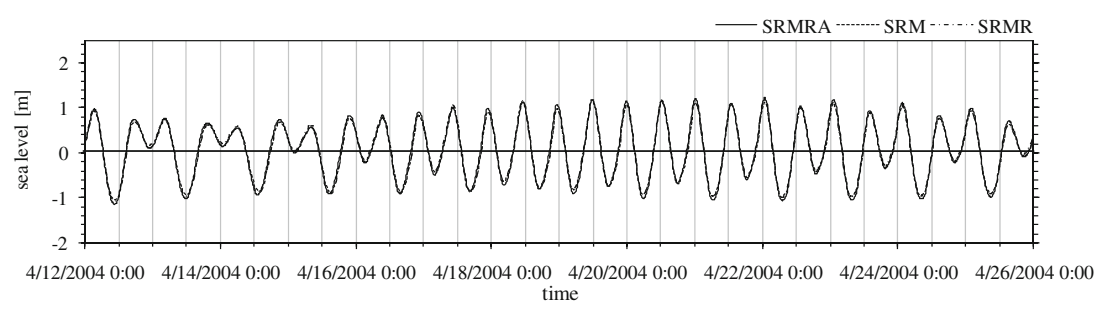

time 
Fig. 6 Time series of depth-averaged tidal current and direction and its comparison with field measurement at $\mathrm{C} 1$

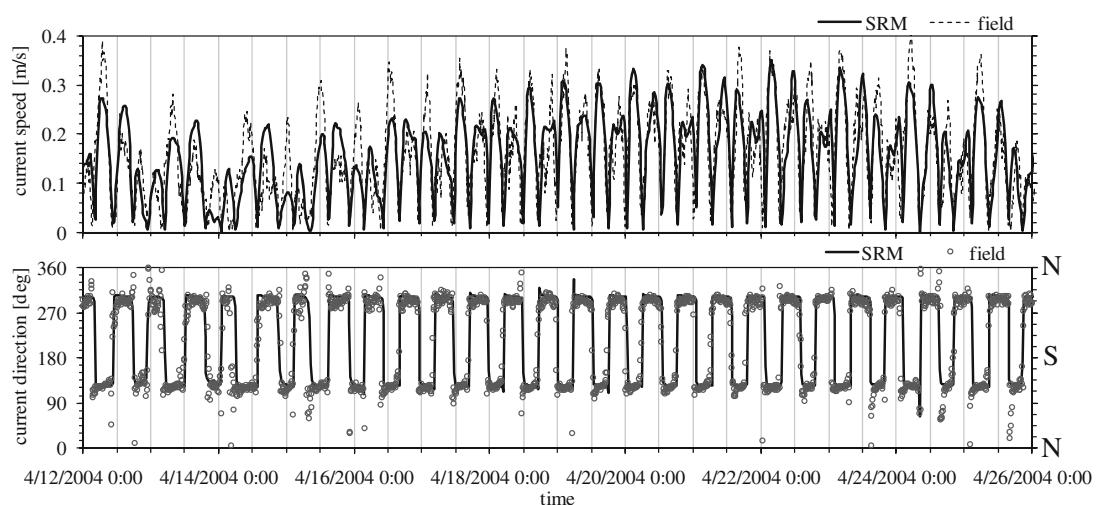

Statistical parameters of mean, standard deviation, standard error and root mean square (RMS) were also estimated for all the three model results during the springneap cycle and compared with field results in order to quantify the model performance (Table 3 ). The parameters for water level variations are very close among the different model results which are in accordance with Fig. 5. However, for current speed and direction, field values are close to SRMRA results, particularly mean and RMS values.

Fig. 7 Time series of computed sea level variation with depthaveraged tidal current and direction and its comparison with field measurement at OL. The $x$ (east) and $y$ (north) components of computed and field currents are displayed in the lower two panels. Solid circles denote the periods of velocity distribution during spring tide as used in Fig. 13
To further validate its accuracy, the SRMRA model was additionally run in a three-dimensional mode, using 10 equidistant sigma layers. The 3D structure of simulated current speed and direction are compared with field measurements during the spring-neap cycle (Fig. 11 with few snap shots in Fig. 12). Visual inspection of this figure reveals that the vertical velocity gradient is larger during the ebb than during the flood (in both the model and the data), resulting probably from fresh water outflow.
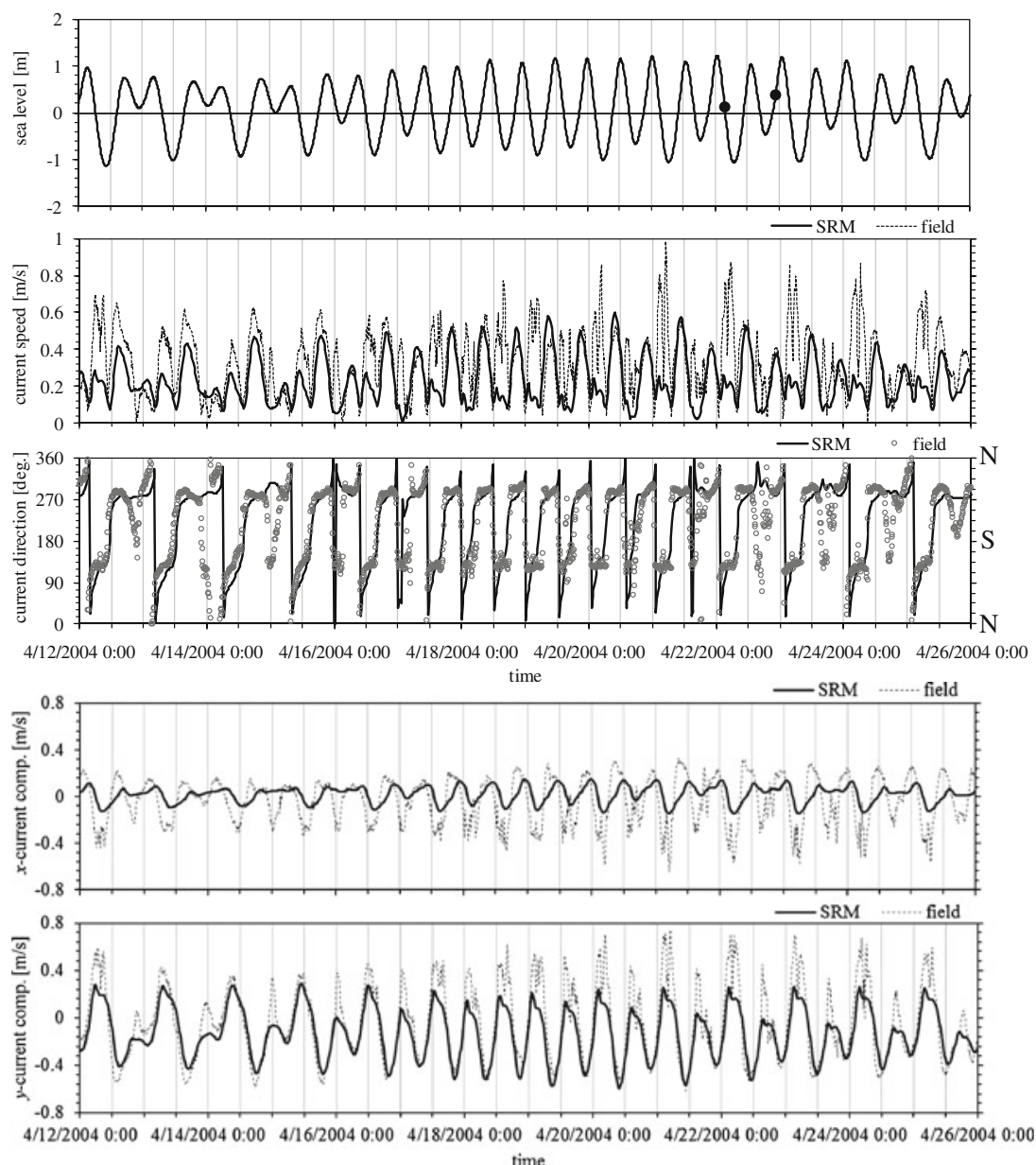
Fig. 8 Time series of simulated depth-averaged tidal current and its direction using the refined grid model (SRMR) and its comparison with field measurement at OL

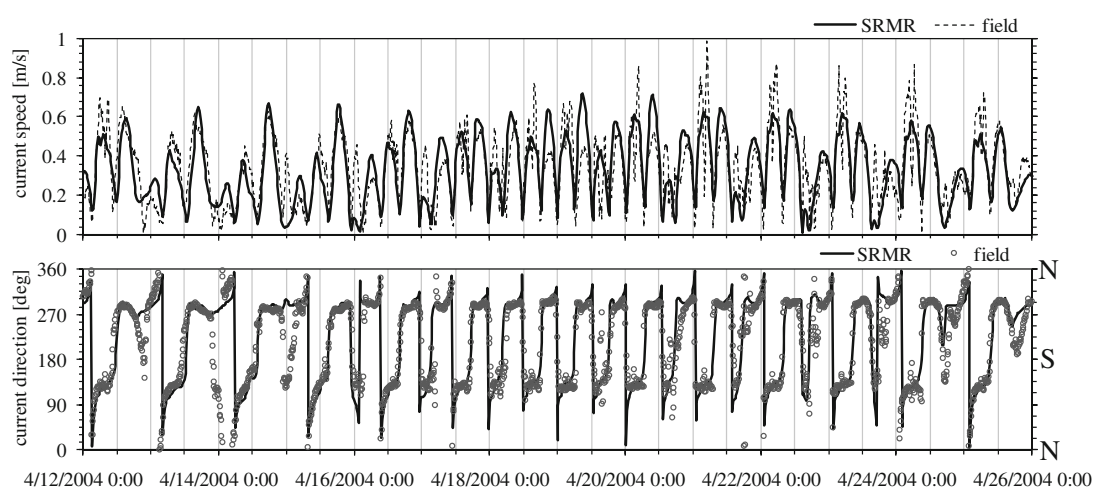

\subsection{Implications for the Johor Estuary}

The computed maximum flows are found higher around Tekong Island using the SRMRA (compared to the SRM and SRMR) and in line with expectations (see Fig. 13). In the Johor Strait (the branch west of the Johor Estuary, separating Singapore from Malaysia), the ebb flow velocities also increase. However, during flood the flow velocity peak is not that much affected, but the location of maximum flow velocity is. Using SRMRA, high flow velocities are predicted in Tekong's western tidal channel. For land reclamation purposes, these are obvious factors to take into account.

The computed ebb flow velocities are larger than computed flood flow velocities throughout the larger part of the model domain (Fig. 14), resulting in predominance of a max ebb/max flood ratio exceeding unity (Fig. 14).
Flow asymmetry can be the result of a residual flow velocity or by tidal asymmetry. A residual flow velocity typically generates a flow asymmetry in which the period of maximum flow velocity exceeds the period of lower flow velocity, whereas the opposite holds for tidal asymmetry (where the period of maximum flow velocity is shorter than the period of lower flow velocities). The asymmetry in the $\mathrm{ebb}$ and flood velocities is related to both residual flow and tidal asymmetry. Near OL, the residual flow is substantial (see Fig. 15). This is also evident from the time series (Fig. 9): the ebb flow velocity is substantially larger than the flood flow velocity, but the duration is also longer. East of Tekong Island, the flood flow velocities peak at $1.2 \mathrm{~m} / \mathrm{s}$, while maximum ebb flow velocities are typically $0.7 \mathrm{~m} / \mathrm{s}$. The residual flow in this area is typically $0.1 \mathrm{~m} / \mathrm{s}$, which implies that this flow asymmetry is due to tidal asymmetry.
Fig. 9 Time series of simulated depth-averaged tidal current and direction using the modified grid model (SRMRA) and its comparison with field measurement at the OL. The $x$ (east) and $y$ (north) components of computed and field currents are displayed in the lower two panels

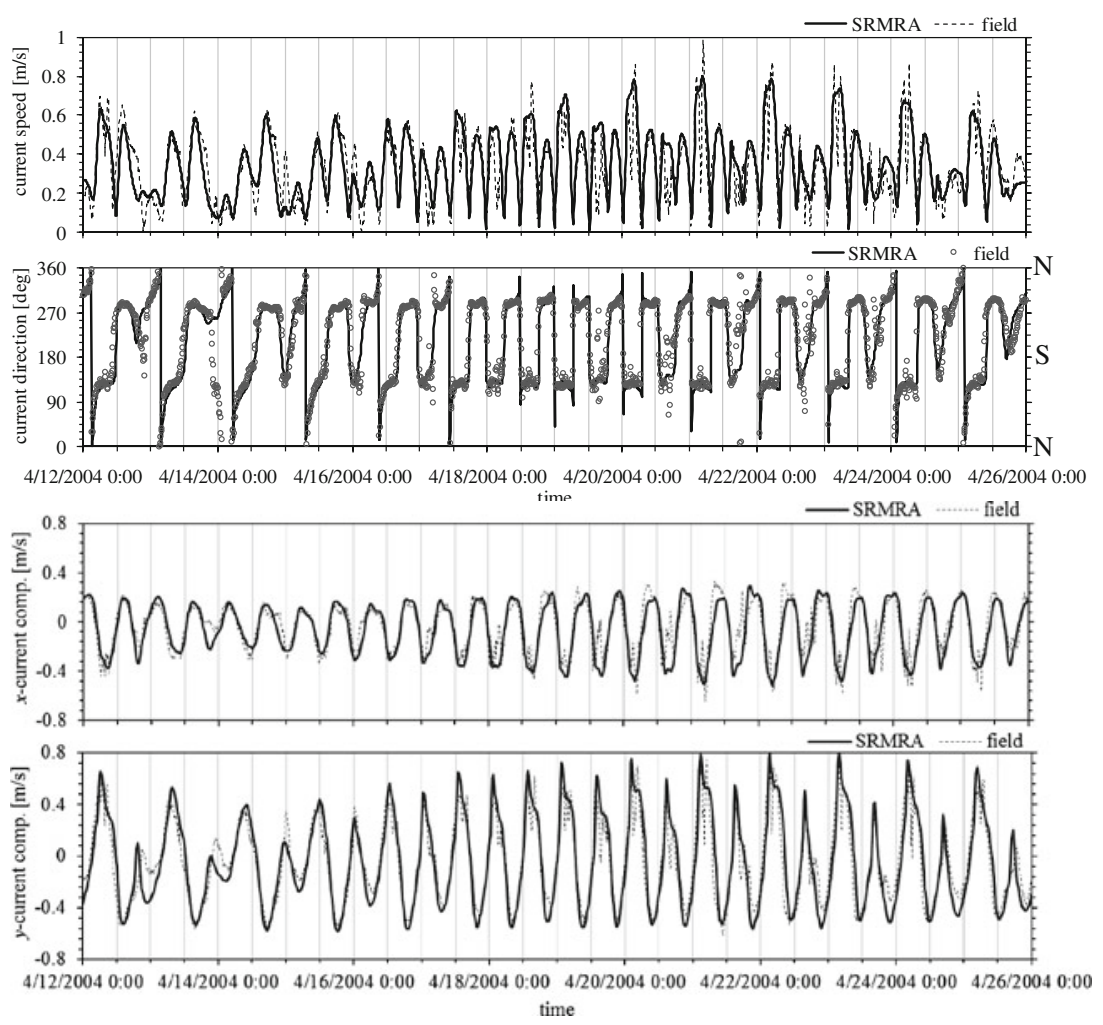


Fig. 10 Velocity rose during the spring-neap cycle (20040412 0:00 h-20040426 $0: 00 \mathrm{~h}$ ) at the OL from the results of different models and field measurements
Table 3 Statistical parameters of the three model result with field measurements
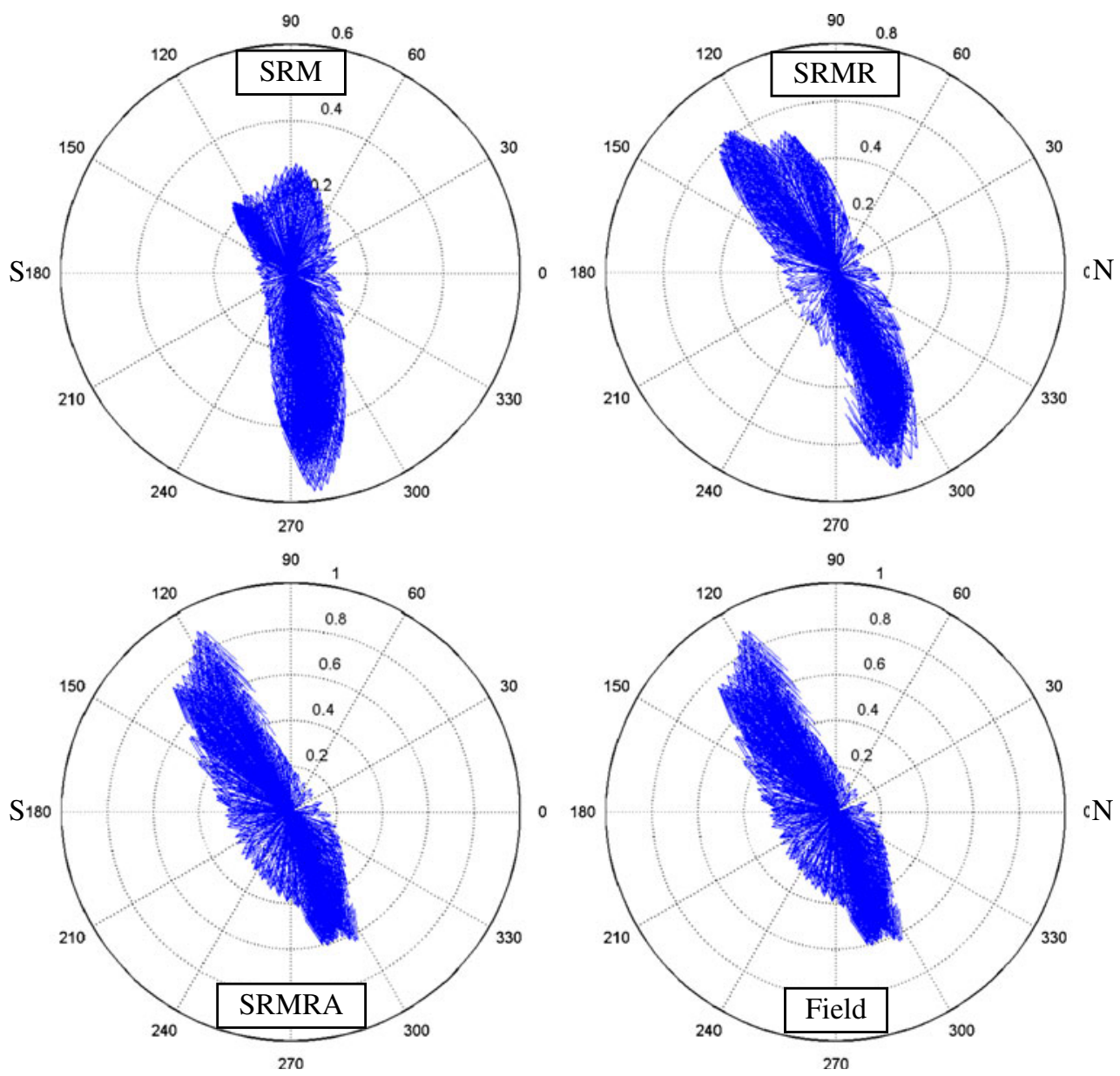

${ }^{\mathrm{CN}}$

\begin{tabular}{llllrl}
\hline Items & & SRM & SRMR & SRMRA & Field \\
\hline Water level [m] & Mean & 0.00 & 0.00 & 0.00 & - \\
& RMS & 0.5937 & 0.6073 & 0.6155 & - \\
& Std. deviation & 0.5940 & 0.6076 & 0.6158 & - \\
& Std. error & 0.0187 & 0.0191 & 0.0194 & - \\
Current speed [m/s] & Mean & 0.2297 & 0.2924 & 0.3815 & 0.3370 \\
& RMS & 0.2631 & 0.3386 & 0.4226 & 0.3785 \\
& Std. deviation & 0.1283 & 0.1708 & 0.1820 & 0.1724 \\
Current direction [m/s] & Std. error & 0.0040 & 0.0054 & 0.0057 & 0.0038 \\
& Mean & 226.58 & 242.39 & 214.28 & 216.06 \\
& RMS & 242.64 & 258.20 & 229.17 & 231.77 \\
& Std. deviation & 86.848 & 88.998 & 81.303 & 83.909 \\
$x$ (east)-current comp. [m/s] & Std. error & 2.7341 & 2.8018 & 2.5595 & 1.8683 \\
& Mean & 0.0174 & 0.0704 & -0.0591 & -0.0371 \\
& RMS & 0.0742 & 0.1419 & 0.2225 & 0.2014 \\
& Std. deviation & 0.0721 & 0.1232 & 0.2146 & 0.1980 \\
& Std. error & 0.0023 & 0.0039 & 0.0068 & 0.0044 \\
& Mean & -0.1281 & -0.1718 & -0.0386 & -0.0452 \\
& RMS & 0.2524 & 0.3074 & 0.3593 & 0.3205 \\
& Std. deviation & 0.2176 & 0.2551 & 0.3574 & 0.3173 \\
& Std. error & 0.0069 & 0.0080 & 0.0113 & 0.0071 \\
\hline & & & & &
\end{tabular}


Fig. 11 Vertical profile of simulated (with SRMRA) tidal current and direction $(\mathbf{a}, \mathbf{c})$ and its comparison with field measurements $(\mathbf{b}, \mathbf{d})$ at $\mathrm{OL}$
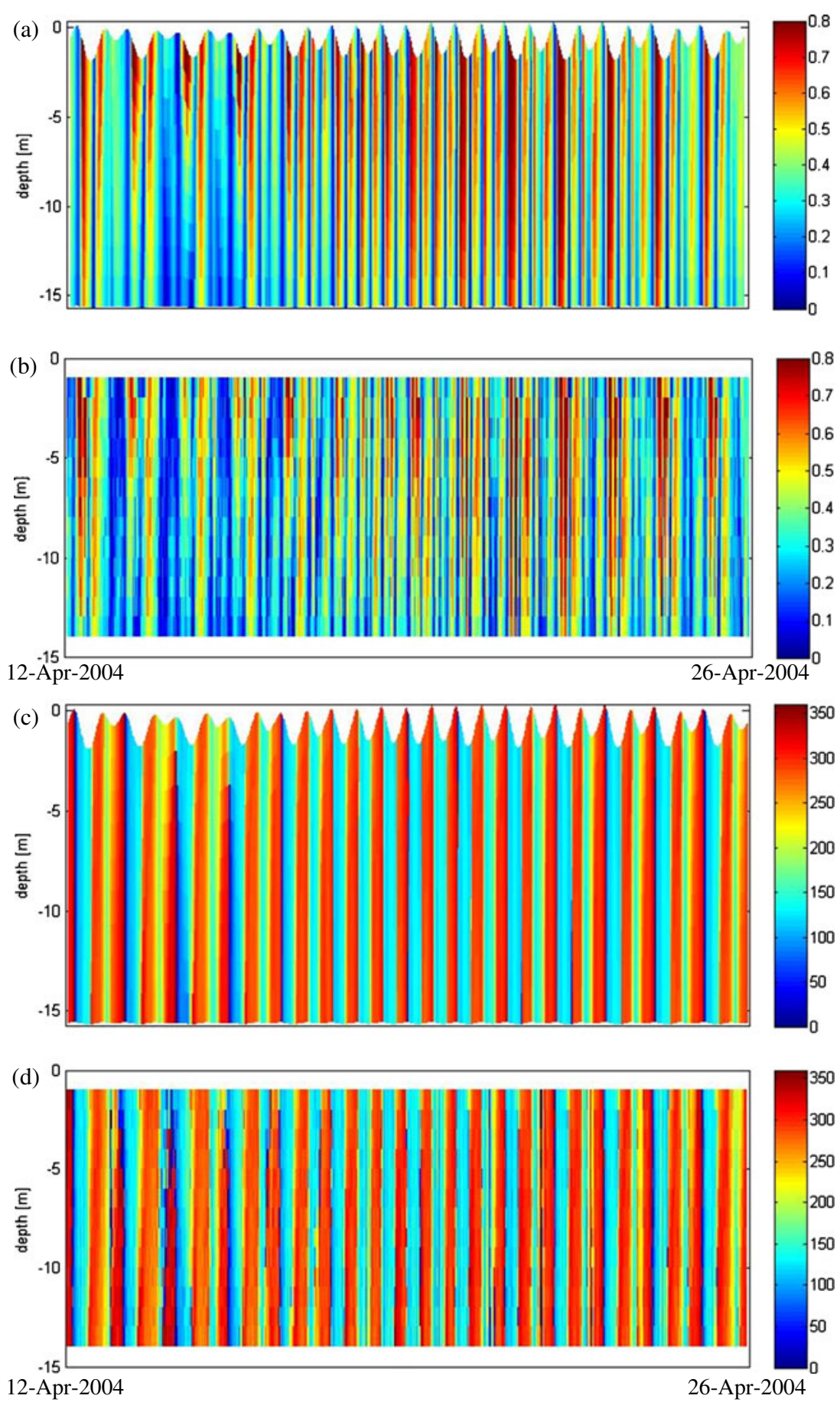

In order to identify and explain the mechanisms responsible for this tidal asymmetry, observed and modeled flow velocities and water levels are harmonically analyzed. Since we are primarily interested in the underlying mechanisms, we focus on the best-performing model, the SRMRA.

Both modeled and observed water levels and velocities are analyzed for 68 harmonic constituents by performing a classical harmonic analysis with nodal corrections using the Matlab version of T-Tide (Pawlowicz et al. 2002). The velocities are first harmonically analyzed in $x$ - and $y$ directions using harmonic analysis that is done similar to that for water levels. These amplitudes and phases in the $x$ and $y$-directions were transformed into tidal ellipses to determine the amplitude and phase of the major axis of the tidal flow (Xu 2000). The dominant constituents in the Johor estuary are the semidiurnal M2 and S2 constituents and the diurnal $\mathrm{O} 1$ and $\mathrm{K} 1$ constituents (Table 4). For both water levels and flow velocities, their amplitude is accurately predicted with an error typically less than $10 \%$. 


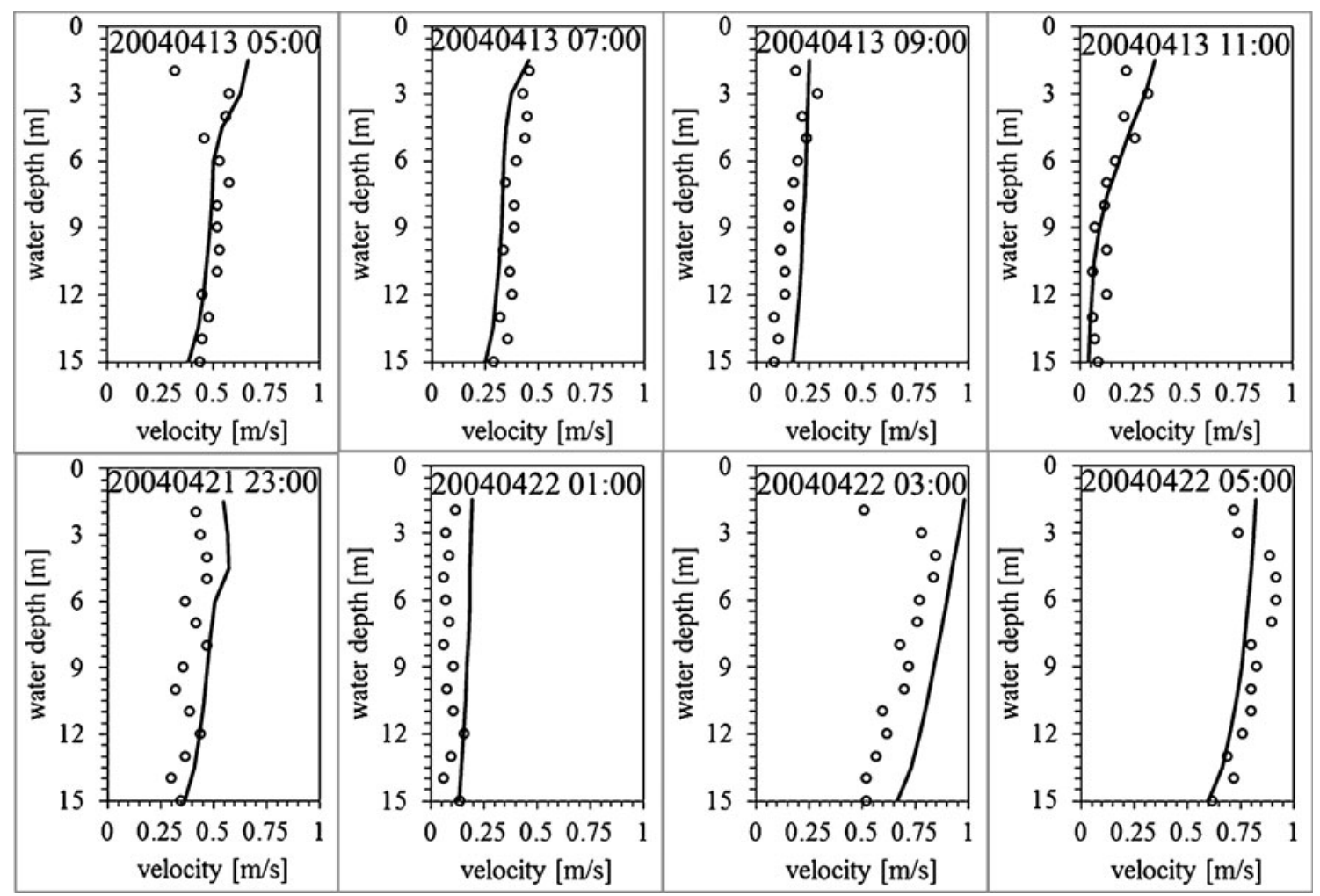

Fig. 12 Snap shots of simulated (with SRMRA) current speed and its comparison with field measurements during neap (upper panels) and spring (lower panels) tidal condition at OL. Empty circles denote field data

Estuarine tidal asymmetry is usually related to the phase relation of M2 with its first overtide M4 through $\theta=\cos$ $\left(2 \phi_{u\left(M_{2}\right)}-\phi_{u\left(M_{4}\right)}\right)$. However, in mixed tidal regimes, tidal asymmetry may also arise from the phase inclination of the O1-K1-M2 triad (Hoitink et al. 2003; van Maren et al. 2004). The harmonic analysis reveals that the velocity amplitudes of the $\mathrm{O} 1, \mathrm{~K} 1, \mathrm{M} 2, \mathrm{~S} 2$, and M4 constituents are $12.0,18.2,45.1,17.2$, and $2.6 \mathrm{~cm} / \mathrm{s}$. Tidal asymmetry resulting from M2 - M4 may only generate a difference between ebb and flood of two times $2.6 \mathrm{~cm} / \mathrm{s}$ or $5.2 \mathrm{~cm} / \mathrm{s}$. This is substantially less than the modeled differences of $50 \mathrm{~cm} / \mathrm{s}$. The maximum difference between ebb and flood currents due to the O1-K1-M2 triad is (M2-O1-K1): $(\mathrm{M} 2+\mathrm{O} 1+\mathrm{K} 1)$, resulting in a potential difference of $60.4 \mathrm{~cm} / \mathrm{s}$. The degree of asymmetry depends on the phase inclination, quantified by Hoitink et al. (2003) as $\theta=\cos \left(\phi_{u\left(O_{1}\right)}+\phi_{u\left(K_{1}\right)}-\phi_{u\left(M_{2}\right)}\right)$. The peak flow velocities are symmetric for $\theta=0$, flood dominant for $\theta=1$, and ebb-dominant for $\theta=-1$. Substituting the phases tabulated in Table 4 reveals that $\theta=-0.8$. This phase inclination varies only little spatially, and therefore, the pronounced flow asymmetries visualized in Fig. 14 are related to the O1-K1-M2 triad. Only in areas where residual flood flow velocities are substantial (mainly topography-induced), the flood flow velocities may exceed ebb flow velocities.
Knowing that the velocity patterns around Tekong Island are substantially influenced by the grid layout, the next question is what its implications are on the tidal propagation and salinity distribution. For that purpose, we visualized the water levels, water level differences with respect to SRM, and salinity for two locations in the upper Johor Estuary (see Fig. 16). The water level amplitude is largest for the SRM and lowest for the SRMR (with the SRMRA in between, but closer to the SRM). It is surprising that the SRMRA results are in between SRM and SRMR, because the data-model comparison indicated that SRMRA was better than SRM and SRMR. The difference between model results for locations $\mathrm{J} 1$ and $\mathrm{J} 2$ is not substantially different, which implies that most of the grid effects arise in the area around Tekong Island. The salinity computed with the SRM is lower than the salinity computed with the SRMRA or the SRMR. This implies that using SRM, less seawater enters the estuary, or less fresh water exits the estuary. In both cases, mixing rates are lower using the SRM. Applying this model to water quality studies or fine suspended sediment transport would, therefore, overestimate residence times and suspended sediment mass (assuming the river is the primary source of sediment) as well as the degree of stratification. 
Fig. 13 Simulated (with SRM, SRMR and SRMRA) tidal current during ebb (a, b and $\mathbf{c})$ and flood (d, $\mathbf{e}$ and $\mathbf{f}$ ) of spring tide. Times for velocity distribution are shown in Fig. 7 by solid circles
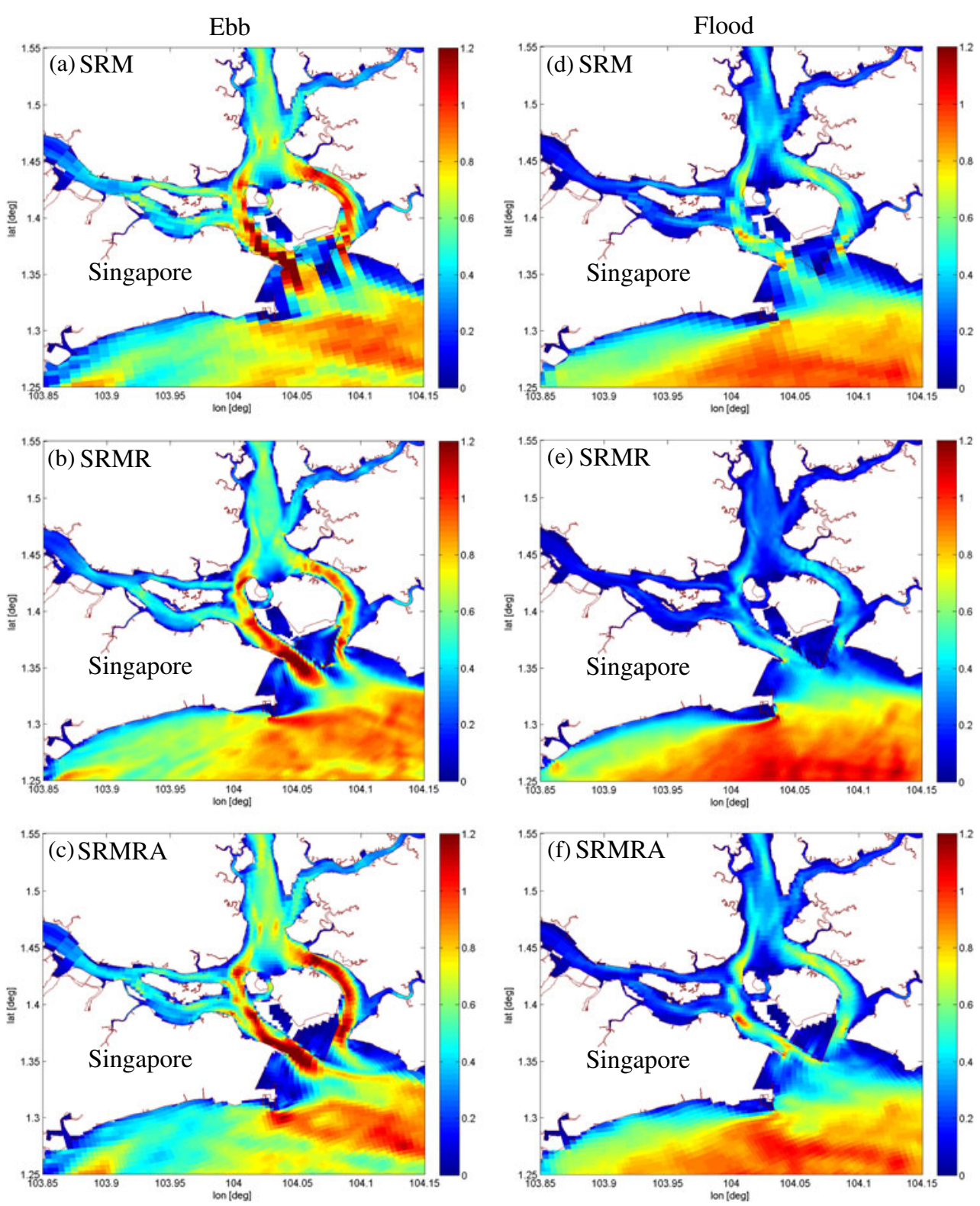

It can be seen that SRM has the largest water level amplitude (suggesting most inflow of marine water) but the lowest salinity (suggesting least marine influence) which is surprising. Without data in the upstream locations, it cannot be substantiated which of the simulations is better (although the downstream model-data comparisons suggest that the SRMRA is better), which particularly show the importance of the grid layout.

\section{Discussion}

The computation results show that the largest difference between the original, the refined, and the refined and aligned grid in the tidal channels are east and west of
Tekong Island (Fig. 13). At their narrowest location, the width is 1 and $1.5 \mathrm{~km}$ (resp.). These channels are covered with $2 / 3$ (resp.) grid cells in the $m$-direction in the SRM but $6 / 9$ (resp.) cells in the SRMR. In the $n$-direction, about five computational cells exist (both east and west channels); hence, 15 in the SRMR model. In the SRM, the low amount of computational cells can be expected to conflict with the ADI scheme, which alternatively solves the model equations in the $m$-direction and $n$-direction. However, it is surprising that improvement due to grid refinement alone (the SRMR) is relatively small. This shows that for models using an ADI solver, grid design should not only focus on refinement aspects, especially on proper alignment with depth contours. The relevance of the work presented here is that even though more and more refined models are being 

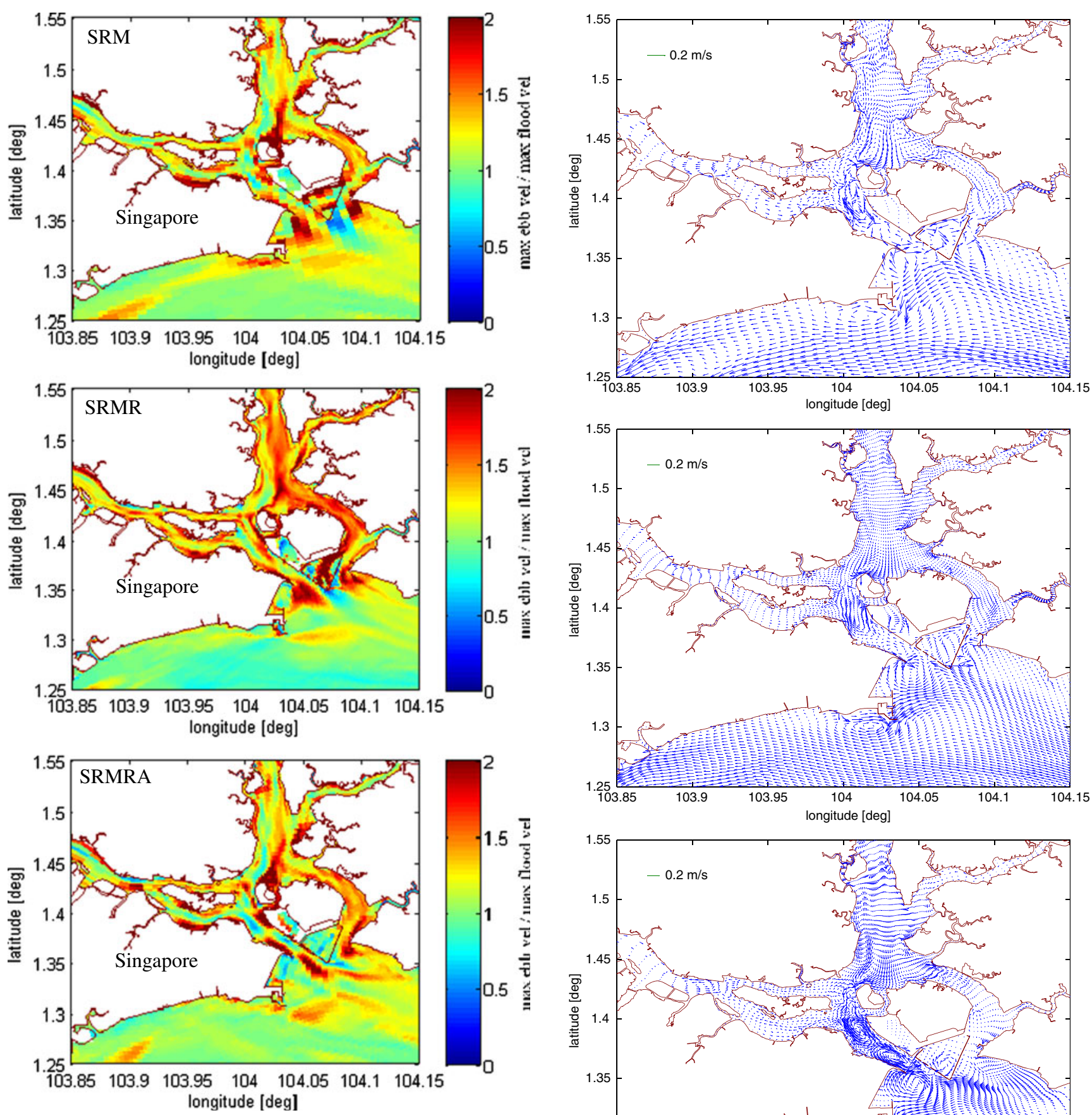

Fig. 14 Ratio of maximum ebb velocity and maximum flood velocity during the spring-neap cycle (20040412 0:00 h-20040426 0:00 h)

setup, especially using computationally demanding unstructured methods, smartly fitted coarse grids could be better than poorly fitted fine grids.

An analysis of the aligned model reveals that the Johor is alternatingly flood-dominant and ebb-dominant. Flood dominance is caused by local residual flows, while the estuary as a whole is ebb-dominant due to tidal asymmetry. This ebb dominance is further strengthened by the downstream-directed freshwater discharge and locally also

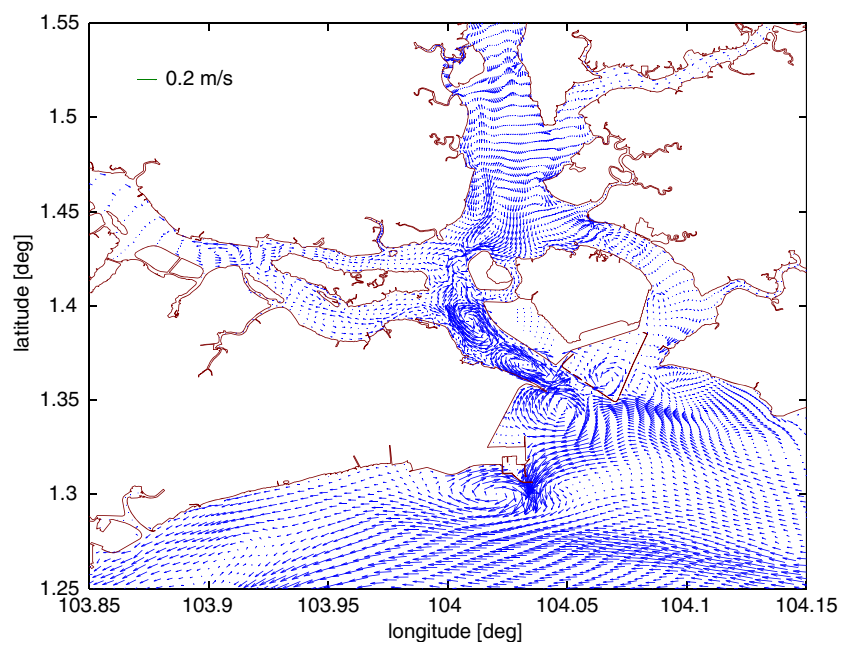

Fig. 15 Mean tidal current computed from the hourly depth average current of one spring-neap cycle for SRM (upper panel), SRMR (middle panel, number of vectors are reduced by a factor of 2) and SRMRA (lower panel).

by topography-induced flows. The tidal asymmetry is caused by the O1-K1-M2 triad. As already noted by Ranasinghe and Pattiaratchi (2000), the asymmetry in 
Table 4 Observed (O) and modeled (M) major axis of the tidal ellipse $(\mathrm{cm} / \mathrm{s})$ with corresponding phase $\phi$, and observed and modeled water levels with corresponding phase $\phi$. All model results and observed flow velocities are at OL station; however, observed water levels are from nearby station $\mathrm{T} 2$
Fig. 16 Sea level variation and its difference, with salinity time series computed by three different models a near the river mouth J1 (upper three panels) and $\mathbf{b}$ near the estuary mouth J2 (lower three panels)

\begin{tabular}{|c|c|c|c|c|c|c|c|c|}
\hline \multirow[t]{3}{*}{ Const. } & \multicolumn{4}{|c|}{ Flow velocity } & \multicolumn{4}{|c|}{ Water levels } \\
\hline & \multicolumn{2}{|c|}{$U_{\text {major }}(\mathrm{cm} / \mathrm{s})$} & \multicolumn{2}{|l|}{$\phi\left(^{\circ}\right)$} & \multicolumn{2}{|c|}{$H(\mathrm{~cm})$} & \multicolumn{2}{|l|}{$\phi\left(^{\circ}\right)$} \\
\hline & $\mathrm{O}$ & M & $\mathrm{O}$ & M & $\mathrm{O}$ & M & $\mathrm{O}$ & M \\
\hline Q1 & 2.0 & 2.8 & 304.3 & 342.2 & 5.1 & 6.2 & 15.0 & 20.6 \\
\hline $\mathrm{O} 1$ & 13.3 & 12.0 & 340.6 & 358.8 & 29.2 & 23.2 & 51.1 & 46.6 \\
\hline P1 & 4.7 & 2.8 & 42.3 & 36.7 & 9.6 & 8.3 & 96.2 & 73.4 \\
\hline $\mathrm{K} 1$ & 15.6 & 18.2 & 26.7 & 39.4 & 29.8 & 29.1 & 104.0 & 97.8 \\
\hline N2 & 7.8 & 7.3 & 226.0 & 227.4 & 15.1 & 12.5 & 298.0 & 301.9 \\
\hline M2 & 39.0 & 45.1 & 246.0 & 254.2 & 75.5 & 70.9 & 321.6 & 330.3 \\
\hline $\mathrm{S} 2$ & 14.6 & 17.2 & 301.5 & 313.2 & 29.9 & 27.1 & 17.1 & 32.4 \\
\hline $\mathrm{K} 2$ & 4.4 & 5.4 & 314.5 & 322.4 & 8.8 & 7.2 & 15.2 & 22.2 \\
\hline M4 & 1.0 & 2.6 & 357.3 & 37.8 & 1.3 & 3.0 & 339.1 & 318.3 \\
\hline
\end{tabular}
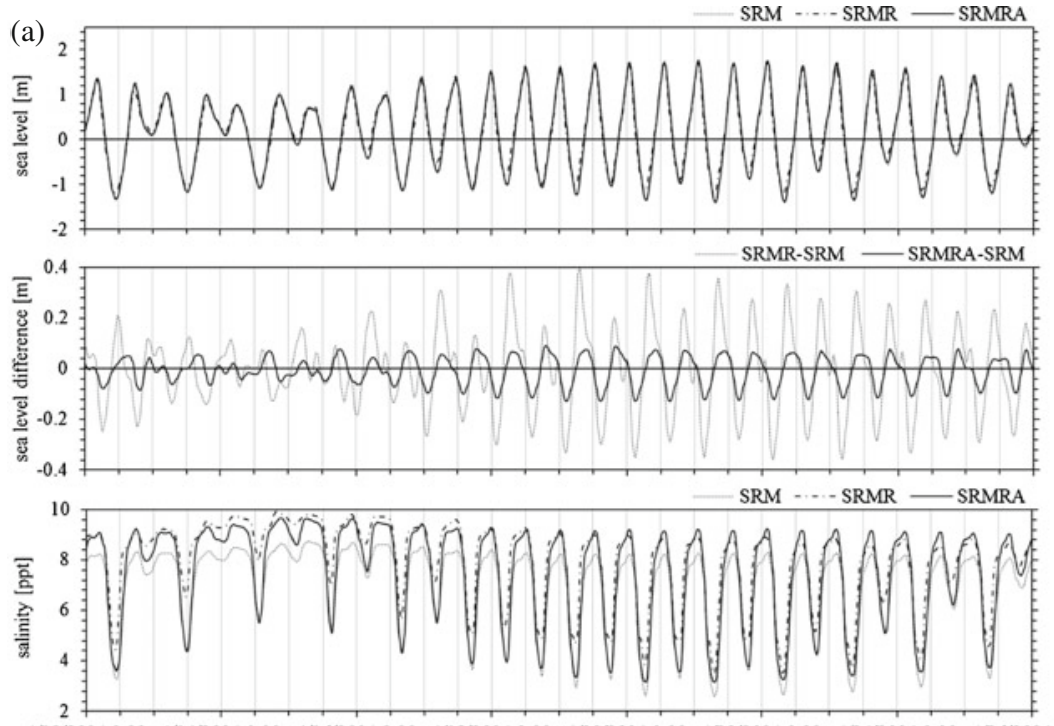

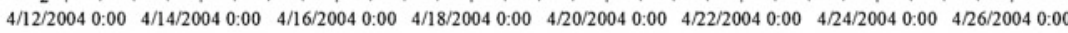
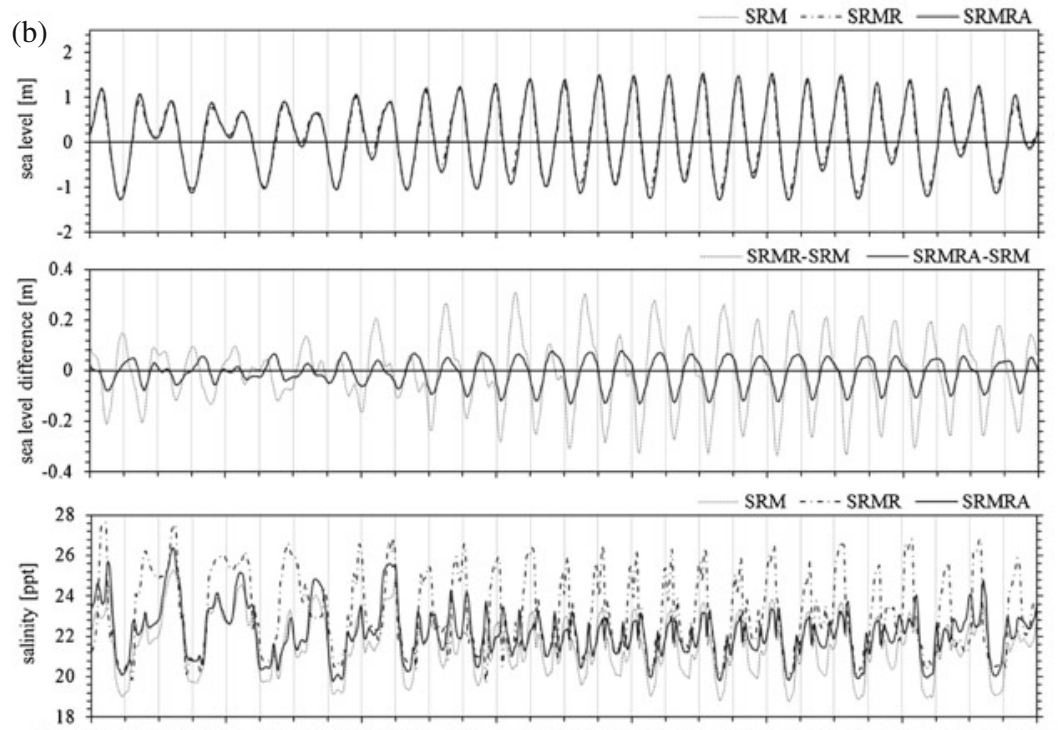

4/12/2004 0:00 4/14/2004 0:00 4/16/2004 0:00 4/18/2004 0:00 4/20/2004 0:00 4/22/2004 0:00 4/24/2004 0:00 4/26/2004 0:0 
estuaries in mixed tidal regimes may strongly depend on oceanic forcing. This asymmetry is very persistent (i.e., Hoitink et al. 2003), which implies that the Johor Estuary is always ebb-dominant. This is in sharp contrast with estuaries worldwide where flood dominance caused by the M4 overtide is common.

\section{Conclusion}

Being between two large water bodies, i.e., Andaman Sea and South China Sea, with different tidal types, hydrodynamics of the Singapore coastal waters are relatively complex. The Singapore Regional Model (SRM) was developed using the Delft3D modeling system to simulate the tidal flows for the whole water bodies between Andaman Sea, South China Sea and part of Java Sea. In order to obtain accurate hydrodynamic information around Singapore, the inner grid of the model particularly near the mouth of the Johor Estuary were modified. The modified model (Singapore Regional Model Refined and Aligned, SRMRA) produces better results due to its finer resolution and more specifically better alignment with narrow channels.

Near the estuary mouth (OL), neap tide is characterized by diurnal currents, while semidiurnal currents dominate during spring tide. Due to the phase difference between O1, $\mathrm{K} 1$, and $\mathrm{M} 2$, a pronounced ebb-dominant asymmetry in the flow exists. The SRMRA better reproduces this asymmetry due to its higher resolution, especially due to the better alignment of the grids in some narrow channels. The importance of grid alignment relative to grid resolution shows that increasing the grid resolution only is not sufficient to substantially improve hydrodynamic models.

Acknowledgement The authors gratefully acknowledge the support of the Singapore-Delft Water Alliance (SDWA) and Jamie Lescinski for her help in redesigning the grid layout. The Maritime and Port Authority of Singapore (MPA) is also acknowledged for providing access to their field data.

\section{References}

Arakawa A, Lamb VR (1977) Computational design of the basic dynamical process of the UCLA general circulation model. Methods Comput Phys 17:173-265

Chao X, Shankar NJ, Hin-Fatt C (1999) A three-dimensional multi-level turbulence model for tidal motion. Ocean Eng 26:1023-1038

Chen M, Chan ES and Khoo BC (1997) Three dimensional circulation model of Singapore coastal waters. Proceedings of Oceanology International 97, Pacific Rim, volume 1

Chen M, Murali K, Khoo BC, Lou J, Kumar K (2005) Circulation modelling in the Strait of Singapore. J Coast Res 21(5):960-972

Davies AM, Kwong SCM, Flather RA (2000) On determining the role of wind wave turbulence and grid resolution upon computed storm driven currents. Cont Shelf Res 20:1825-1888
Deleersnijder E, Lermusiaux P (2008) Multi-scale modeling: nested-grid and unstructured-mesh approaches. Ocean Dyn 58:335-336

Doorn-Groen SM (2007) Environmental monitoring and management of reclamation works close to sensitive habitats. Terra et Aqua 108:3-8

Hasan GMJ, Hin-Fatt C, van Maren DS (2010) Preliminary study on response of suspended sediment concentration to tidal dynamics of a large estuary. Proceedings in the 19th KKNN Symposium on Environmental Engineering, Kyoto, Japan, pp. $1-12$

Hoitink AJF, Hoekstra P, van Maren DS (2003) Flow asymmetry associated with astronomical tides: implications for the residual transport of sediment. J Geophys Res 108(C10). doi:10.1029/ 2002JC001539

Jones JE, Davies AM (2007a) On the sensitivity of tidal residuals off the west coast of Britain to mesh resolution. Cont Shelf Res 27:64-81

Jones JE, Davies AM (2007b) On the sensitivity of computed higher tidal harmonics to mesh size in a finite element model. Cont Shelf Res 27:1908-1927

Ooi SK, Zemskyy P, Sisomphon P, Gerritsen H and Twigt D (2009) The effect of grid resolution and weather forcing on hydrodynamic modeling of South East Asian waters. Proceedings of the 33rd IAHR congress, Vancouver, Canada, 8 pages

Pang WC, Tkalich P and Chan ES (2003) Hydrodynamic forecast model for the Singapore Straits. Proceedings of the 30th IAHR congress, Thessaloniki, Greece, pp. 9-16

Pawlowicz R, Beardsley R, Lentz S (2002) Classical tidal harmonic analysis including error estimates in MATLAB using T TIDE. Comput Geosci 28:929-937

Pugh, D.T. (1987). Tides, surges and mean sea level. Wiley. ISBN 047191505, 472 pages.

Ranasinghe R, Pattiaratchi C (2000) Tidal inlet velocity asymmetry in diurnal regimes. Cont Shelf Res 20:2347-2366

Shankar NJ, Hin-Fatt C, Chan CT (1997) Boundary fitted grid models for tide motions in Singapore coastal waters. J Hydraul Res 35 (4):47-60

Stelling G (1984) On the construction of computational methods for shallow water flow problems. PhD Thesis, Rijkswaterstaat communication series No. 35, The Hague, Rijkswaterstaat

Stelling G, Leendertse I (1991) Approximation of convective processes by cyclic ADI methods. In: Spaulding ML et al (eds) Proc. Estuarine and Coastal Modelling. ASCE, New York, pp $771-782$

Twigt D (2007) Seasonal, climatological boundary forcing for the Singapore Regional Model. Internal research report prepared for MHBox project, WL|Delft hydraulics (Deltares)

van Maren DS, Hoekstra P, Hoitink AJF (2004) Tidal flow asymmetry in the diurnal regime: bed load transport and morphologic changes around the Red River Delta. Ocean Dyn 3-4:424-434

Warner JC, Geyer WR, Arango HG (2010) Using a composite grid approach in a complex coastal domain to estimate estuarine residence time. Comput Geosci 36:921-935

Wyrtki K (1961) Physical oceanography of the south east Asian waters. University of California, La Jolla, California, p 195

$\mathrm{Xu} \mathrm{Z}$ (2000) Ellipse parameters conversion and vertical velocity profiles for tidal currents. Bedford Institute of Oceanography, Dartmouth, Nova Scotia, Canada, p 20

Zhang QY (2006) Comparison of two three-dimensional hydrodynamic modeling systems for coastal tidal motion. Ocean Eng 33:137-151

Zhang QY, Chan ES (2003) Sensitivity studies with the threedimensional multi-level model for tidal motion. Ocean Eng 30:1489-1505 
Zhang QY, Gin KYH (2000) Three-dimensional numerical simulation for tide motion in Singapore's coastal waters. Coast Eng 39:71-92

Zijl F and Kernkamp HWJ (2004) Further hydraulic model studies for Pulau Ubin and Pulau Tekong reclamation scheme. Delft
Hydraulics Report Z3437 for Housing and Development Board (HDB)

Zu T, Gan J, Erofeeva SY (2008) Numerical study of the tide and tidal dynamics in the South China Sea. Deep-Sea Res I 55: $137-154$ 